\title{
El ganado bovino criollo patagónico de Argentina
}

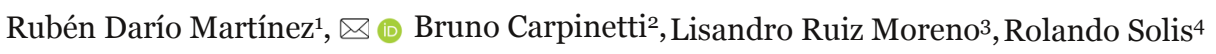

Facultad de Ciencias Agrarias. Universidad Nacional de Lomas de Zamora (UNLZ). Argentina

\section{Patagonian Creole cattle of Argentina}

\begin{abstract}
The Patagonian Creole cattle from Argentina is a zoogenetic resource formed in Patagonia, with the biological characteristics that are required to live and produce in such beautiful environments, how harsh and changing. The diversity of their fur and their morphology (favorable condition for extensive Patagonian production), was punished by the market, which has preferred to use uniform breeds. Also in the academic field there were and still are today advocates of uniformity against diversity. Today we know that biological evolution is impossible without genetic and phenotypic diversity and animal production (especially extensive and in extreme and changing environments) needs to evolve to be efficient. Currently, Creole cattle are present in all Patagonian provinces, in some there are feral populations in protected areas or public lands, and there are also private producers who develop different productive approaches with Creole cattle. This work describes some genetic characteristics of the resource and provides an updated overview of its development in the region. The rational use of this genetic resource, considering its adaptive advantages, could have an important positive impact in improving livestock productivity in the entire Patagonian region, through the contribution of genes and gene combinations related to fertility, rusticity, meekness, longevity and all those attributes that the bovine species requires to develop in extensive productions with difficult and changing environments, as occurs throughout the Patagonian region.
\end{abstract}

Key words: genetic diversity; zootechny; bovinae; rural environmental

Resumen. El ganado bovino criollo patagónico de Argentina es un recurso zoogenético formado en la Patagonia, con las características biológicas que se requieren para vivir y producir en esos ambientes tan bellos, como duros y cambiantes. La diversidad de sus pelajes y su morfología (condición favorable para la producción extensiva patagónica), fue castigada por el mercado que ha preferido utilizar razas uniformes. También en el ámbito académico existieron y existen aún hoy, defensores de la uniformidad frente a la diversidad. Hoy sabemos que la evolución biológica es imposible sin diversidad genética y fenotípica y la producción animal (sobre todo la extensiva y en ambientes extremos y cambiantes) necesita evolucionar para ser eficiente. Actualmente el bovino criollo se encuentra presente en todas las provincias patagónicas, en algunas hay poblaciones asilvestradas en áreas protegidas o tierras públicas y también privados, que desarrollan distintos planteos productivos con bovinos criollos. Este trabajo describe algunas características genéticas del recurso y brinda un panorama actualizado de su desarrollo en la región. La utilización racional de este recurso genético, considerando sus ventajas adaptativas, podría tener un importante impacto positivo en la mejora de la productividad ganadera de toda la región patagónica, mediante el aporte de genes y combinaciones de genes relacionados con la fertilidad, la rusticidad, la mansedumbre, la longevidad y todos aquellos atributos que requiere la especie bovina para desarrollarse en producciones extensivas con ambientes difíciles y cambiantes como ocurre en toda la región patagónica.

Palabras clave: diversidad genética; zootecnia; bovina; ambiente rural

Recibido: 2020-07-24. Aceptado: 2020-10-26

1Autor para la correspondencia: martinezruda@yahoo.com.ar

²́rea de Gestión Ambiental y Ecología. Universidad Nacional Arturo Jauretche (UNAJ)

3 Productor ganadero, Actividad privada

${ }^{4}$ Ingeniero Zootecnista, Asesor agropecuario 


\section{Introducción}

Los bovinos criollos se originan en América a partir de los animales introducidos por los colonizadores durante los primeros años de la conquista (Rouse, 1977). Se encuentran distribuidos en diferentes regiones y países, sosteniendo sistemas de producción tanto de carne como de leche, desde zonas muy bajas como es el trópico húmedo hasta los ecosistemas andinos, indicando evoluciones diferentes en cada caso (Tewolde, 1997). Este proceso dio origen a los ganados criollos actuales, que son verdaderas joyas genéticas: el Bos taurus puro adaptado a los trópicos y a otros climas extremos del continente (De Alba, 2011). En Argentina, los primeros ejemplares fueron siete vacas y un toro que ingresaron en 1549, traídos por los hermanos Gois desde San Vicente Brasil hasta Asunción (Montoya, 1984). Las vías de ingreso fueron cuatro: por el Noroeste (desde Perú por Bolivia o Chile), por el norte (por Paraguay) por el Este (Brasil) y por el Río de la Plata (Giberti, 1970). Las vacas tuvieron una importancia crucial como proveedoras de carne y cuero, pero fundamentalmente como bien de cambio (el grueso del comercio, giraba alrededor de las vacas). Si bien los indios aprendieron, e incluso inventaron técnicas para el manejo del caballo, también lo hicieron para el manejo y cría de vacunos y lanares. Hay muchas menciones de la existencia de ganado manso sobre todo en grupos pampeanos y norpatagónicos y también se observa la construcción de corrales para vacas y ovejas en algunos casos (Bustos, 1993). Hacia 1850, el 90 \% de la población bovina criolla del país se ubicaba en la región pampeana, donde existían en esa fecha unos 20000 ooo de cabezas (Lebedinsky, 1967). En ese momento comienza en ésta región, el proceso de mestización del bovino criollo, principalmente con reproductores de las razas británicas Shorthorn, Hereford y Aberdeen Angus, reduciéndose paulatinamente el número de bovinos criollos en estado de pureza racial en la zona templada, para ir a poblar aquellos ambientes donde las razas introducidas no resultaron productivas. Según el censo de 1937, la existencia total de bovinos criollos era de 6664403 animales difundidos en su gran mayoría en el norte del país, donde se adaptaron por su rusticidad y resistencia a las enfermedades parasitarias e infectocontagiosas (Inchausti y Tagle 1980). Durante todo el siglo XX e incluso en la actualidad, la selección del ganado en general y del bovino en particular estuvo orientada a lograr poblaciones fenotípicamente lo más uniformes posibles (pelajes, tamaño, crecimiento, peso y conformación en general). Cuando el objetivo era que los animales sean de tamaño pequeño debían ser uniformes, luego cuando el objetivo fue el tamaño grande también debían ser uniformes y ahora que el objetivo es que el tamaño sea moderado también deben ser uniformes. Como consecuencia de esta orientación selectiva lo que se va perdiendo paulatinamente es la diversidad. Esta búsqueda de uniformidad fenotípica es contraria a la selección natural, la naturaleza se ocupa a través de distintos mecanismos de generar variabilidad genética y fenotípica, que son el motor de la evolución. El bovino criollo argentino, formado principalmente a partir de un proceso de selección natural de aproximadamente quinientos años (Rabasa et al. 2005), se mantuvo al margen de esta corriente selectiva, lo que le ha permitido desarrollarse en los más diversos ambientes de nuestro país logrando excelentes resultados productivos $\mathrm{y}$ al mismo tiempo mantener su heterogeneidad natural. La diversidad del bovino criollo, contrasta fuertemente con el ideal de uniformidad bovina, por lo cual la raza ha sido castigada no solo comercialmente con menores precios, sino también en el ámbito académico, para lo cual podemos citar textualmente algunas de las afirmaciones realizadas en distintos libros de texto y artículos académicos: "el esmirriado ganado criollo" (Helman, 1986); "el raquítico bovino criollo tiene carne enjuta y dura" (Sesto, 2004); "son de líneas angulosas y alargados, espaldas inclinadas y poco musculosas, tórax estrecho y no muy profundo, nalgas descarnadas, vientre levantado, de esqueleto fuerte y masas musculares escasas que no alcanzan a cubrir las apófisis espinosas de las vértebras, lo cual da aspecto cortante a las regiones del dorso y lomo, los miembros son largos con huesos desarrollados" (Inchausti y Tagle, 1980); "son de escaso valor comercial, excepto por sus cueros" (Ensminger, 1973); "son flacos, pequeños, huesudos y sin carnadura” (Sesto, 2004); "son bovinos altos, huesudos, más bien angostos, con largos cuernos" (Mareco, 2013); "el bovino criollo carece de factores hereditarios determinantes de una buena producción de carne o leche" (Helman, 1983); "su escaso valor actual, de talla reducida, lenta evolución, cuernos grandes, apariencia angulosa, pelajes desuniformes, sus bajos rendimientos de carne o leche y su deficiente procreación, ofrece un conjunto de aptitudes muy inferiores" (Helman,1983); "son de porte pequeño, desuniformes y muy poco productores de carne o leche" (Helman, 1986). La ganadería bovina argentina es mayoritariamente de tipo extensivo y pastoril por lo cual requiere de razas que puedan adaptarse a los cambios climáticos que ocurren en las distintas regiones. El clima es muy variable en todas las regiones (en algunas, es más marcado que en otras) y la posibilidad de mantener producciones ganaderas estables en ambientes cambiantes no se da con razas uniformes, sino con razas ganaderas que presenten 
diversidad genética y fenotípica suficiente para poder adaptarse a estos cambios y seguir produciendo con la menor dependencia de insumos externos. La raza bovina criolla argentina está distribuida a lo largo y ancho de todo el país, también en el extremo sur, el ganado bovino criollo patagónico. El objetivo del trabajo es difundir algunas características genéticas de los bovinos criollos patagónicos y destacar su presencia actual en todas las provincias patagónicas, a efectos de fomentar su utilización en planteos productivos, teniendo en cuenta que su diversidad, favorece la eficiencia de los sistemas extensivos y el cuidado ambiental.

\section{Bovino Criollo Patagónico}

Ninguna de las embarcaciones que llegaron desde el continente europeo directamente a la Patagonia trajeron caballos y vacunos, estos ingresaron desde el norte por vía terrestre (Lafuente, 1981). En 1741 Bulkeley y Cummins, marinos ingleses sobrevivientes del buque Wager, observaron la presencia de tehuelches a caballo cerca del Cabo Vírgenes arreando una cantidad de ganado vacuno, luego en 1781 , son observados en el Puerto San Julián (Palermo, 1988). Los primitivos habitantes de la patagonia argentina, los Tehuelches, no desarrollaron una marcada vocación ganadera, utilizaron el ganado vacuno principalmente como bien de cambio, para obtener caballos y otros productos que les proveían las tribus vecinas (Gotta, 1993). No fueron grandes consumidores de carne vacuna, aunque desarrollaron algunos subproductos con el cuero y otras partes de los bovinos, como tapices y otros utensilios (Hay muestras de ello en el Museo de Ciencias Naturales de la Universidad Nacional de La Plata). Recién a fines del siglo XIX se afianzó el predominio del hombre blanco, por lo cual el desarrollo de la actividad bovina, estuvo a cargo exclusivo de los habitantes nativos hasta esa fecha. Si bien estos se destacaron en la invención de técnicas para el manejo de los caballos, también incorporaron técnicas de manejo y cría para los vacunos, así fue como a partir de manadas de vacas cimarronas los indios pampas y los norpatagónicos poco a poco fueron logrando rodeos propios de animales mansos para comercializar o consumir, para ello se valieron de la construcción de corrales (Palermo, 1988). Este primer período en la formación del Criollo Patagónico se caracterizó por la reproducción libre, donde tuvo gran importancia la selección natural para determinar que animales dejaban descendencia. Los indígenas le otorgaron gran importancia al comportamiento y a la facilidad de manejo, por lo cual tienen que haber realizado selección artificial a favor de la mansedumbre pues se observa que, a fines del siglo XIX, mantienen algunos grupos de vacunos mansos cerca de las viviendas, que eran manejados por las mujeres y los niños (Palermo, 1988). La fundación de las poblaciones de Carmen de Patagones en la provincia de Río Negro (1779) y Colonia Floridablanca en San Julián provincia de Santa Cruz, favorecieron la llegada y la difusión del ganado bovino en la Patagonia, pero el mayor desarrollo va a comenzar casi un siglo después con la colonización galesa en la provincia de Chubut (1865), con la Colonia Pastoril de Santa Cruz (1868) y con la implementación de un plan de fomento ganadero que estableció Carlos M. Moyano, el primer gobernador de la provincia de Santa Cruz, que consistía en el ingreso de animales vía terrestre desde la zona pampeana a través de la Ruta de los Tehuelches o Camino de los Arreos (camino precordillerano que unía Río Negro con Santa Cruz). Esta vía de ingreso fue la más utilizada a partir del año 1884, ésta era una vía adecuada para transportar entre 4 y 5000 cabezas de ganado sin ninguna dificultad (Moyano, 1968). A partir de estos bovinos se fueron consolidando varios establecimientos ganaderos en la provincia de Santa Cruz, donde el vacuno criollo se utilizaba como animal de triple propósito carne-leche-trabajo, destacándose por su mansedumbre, rusticidad y resistencia (Morrison, 1917). El proceso de mestización del bovino criollo patagónico ocurrió más tardíamente, acrecentándose a mediados del siglo XX. Recién en 1989, fue descripta una población de ganado bovino criollo asilvestrado en un sector del Parque Nacional Los Glaciares, provincia de Santa Cruz (Rodríguez et al. 1989). A partir de entonces, la Facultad de Ciencias Agrarias de la Universidad Nacional de Lomas de Zamora, inició un programa de recuperación conservación y caracterización de este germoplasma que consiste básicamente en preservar, conocer y difundir este invalorable material genético bovino formado mediante la selección natural en un ambiente frio de la Patagonia sur de Argentina. Este programa mantiene un núcleo genético "in vivo" "ex situ", ubicado actualmente en dos localidades de la provincia de Buenos Aires, Chascomús y Tornquist y un banco de germoplasma con semen congelado. Además, existen otras poblaciones y rodeos ubicados en distintas provincias patagónicas. Se describen algunas características genéticas de este recurso y se hace una revisión de su distribución actual en las provincias patagónicas.

\section{Características Genéticas}

La población de bovinos criollos asilvestrada en el Parque Nacional Los Glaciares, se mantuvo cerrada, bajo reproducción libre durante más de veinte 
generaciones. Durante ese lapso han ocurrido cambios climáticos muy importantes, aun así, la población ha sobrevivido manteniéndose saludable, seguramente debido a la acción de la selección natural, que favorece la reproducción de los animales con mejores condiciones fenotípicas, manteniendo la variabilidad genética de la población. Debido al aislamiento reproductivo, muchas personas adhirieron a la creencia que se trataba de animales con una consanguinidad muy elevada y que debido a ello los animales "degeneraban" y el síntoma era que presentaban pelajes de todos colores. Es conocido que el mantenimiento de la variabilidad genética de las poblaciones depende de la cantidad y diversidad de gametas presentes en cada evento reproductivo y eso se puede estimar mediante un parámetro denominado Tamaño Efectivo de la población (Falconer y Mackay, 2001). Cuanto mayor es este parámetro, menor es el incremento de la consanguinidad y por lo tanto también será menor la pérdida de variabilidad genética. En éste caso, en la población de bovinos criollos, el Tamaño Efectivo es el máximo posible ya que todos los años, existe el mismo número de hembras que de machos habilitados para la reproducción y los apareamientos son totalmente aleatorios, regulados por la naturaleza. Por ejemplo, si suponemos que la población asilvestrada está compuesta por 1000 animales reproductivos (500 hembras y 500 machos), su tamaño efectivo será igual a mil $(\mathrm{Ne}=1000)$, lo cual equivale a un incremento de la consanguinidad de $(\Delta \mathrm{F}=0.0005)$ por generación. Podemos comparar estos valores con el manejo reproductivo que se realiza de manera corriente en los rodeos bovinos utilizando un $3 \%$ de machos reproductivos donde entonces tendríamos para un total de 1000 animales (970 hembras y 30 machos), el Tamaño Efectivo de esta población es igual a ciento dieciséis $(\mathrm{Ne}=116)$ y el incremento de la consanguinidad $\Delta \mathrm{F}=0.0043$ por generación. Se observa entonces que en la población asilvestrada de bovinos criollos patagónicos, el incremento de la consanguinidad por generación es despreciable respecto de los valores que se registran habitualmente en las poblaciones bajo esquemas productivos, donde incluso podrían verificarse incrementos mayores de la consanguinidad, si se utilizara semen de un solo toro para servir a las vacas mediante inseminación artificial. Respecto a los pelajes de todos los colores y variantes, no se trata de una degeneración, es la manifestación externa de la salud genética de la población, que manifiesta la presencia de muchas variantes posibles para adaptarse mejor al ambiente cambiante, además de constituir una fiesta del color que le otorga a la población una belleza muy particular. La heterogeneidad genética y fenotípica es lo que le ha permitido a esta población vivir y desarrollarse en situaciones ambientales muy cambiantes y extremas. Es difícil imaginar que una población de animales con características genéticas y fenotípicas uniformes, pueda sobrevivir asilvestrada y adaptarse a cambios climáticos tan importantes.

\section{Descripción genética mediante marcadores moleculares}

Se muestrearon 36 bovinos criollos patagónicos y se genotiparon para veintisiete marcadores microsatélites recomendados por FAO para la caracterización de poblaciones (Martínez, 2008). El genotipado se realizó en el laboratorio de Genética Molecular de la Facultad de Veterinaria de la Universidad de Córdoba, España. Como resultado del mismo, se detectaron en total ciento treinta y seis (136) variantes alélicas. El número de alelos por locus (Na) varió desde ocho (8), para los microsatélites CSSM66 y HAUT27 y tres para los loci BM8125; ILSTSo11 e INRA63, con una media de 5.04 alelos por locus. Ninguno de los microsatélites mostró variantes con frecuencias superiores a 0.95, por lo cual los veintisiete marcadores resultaron polimórficos. Los valores de heterocigosidad media esperada ( $\mathrm{He})$, y heterocigosidad media observada (Ho) fueron de 0.6107 y 0.5795 respectivamente. El valor máximo de He corresponde al locus CSSM66 (o.7948) y el mínimo al HEL13 (0.1798). El contenido de información polimórfica PIC depende tanto del número de alelos como de la distribución de sus frecuencias en la población. Los valores altos para un marcador indican que es muy informativo, mientras que los bajos significan menor información. El promedio de PIC fue de 0.5612 para un Na promedio de 5.04 por marcador. En resumen, 20 marcadores fueron altamente informativos con valores mayores de 0.50, seis fueron medianamente informativos con valores entre $0.25 \mathrm{y}$ 0.50 y uno solo con bajo valor informativo menor a o.25. El Fis mide la reducción en la heterocigosidad debida a los apareamientos no al azar en la subpoblación, por lo cual indica el nivel de endogamia de los individuos de la subpoblación. Es una correlación estadística que toma valores desde $-1 \mathrm{a}+1$. El signo negativo indica heterocigosis mientras que el signo positivo indica homocigosis. La magnitud del Fis Multilocus fue de 0.06579, lo cual indica un valor bajo de endogamia en la población.

\section{Distancia Genética entre el Criollo Patagónico (PAT) y el del Noroeste (NOA)}

Se estimaron cuatro distancias genéticas entre las poblaciones de PAT $(\mathrm{n}=36)$ y NOA $(\mathrm{n}=45)$, utilizando 27 marcadores microsatélites (Martínez, 2008), los resultados se observan en el Cuadro 1. 
Cuadro 1. Distancia genética entre poblaciones

\begin{tabular}{lcccc}
\hline & \multicolumn{4}{c}{ Medidas de Distancia genética entre ambas poblaciones } \\
\hline Poblaciones & $\begin{array}{c}\text { Estándar Nei } \\
\text { (Ds) (1972) }\end{array}$ & $\begin{array}{c}\text { Reynolds } \\
\text { (DR) (1983) }\end{array}$ & $\begin{array}{c}\text { Cavalli Sforza } \\
\text { (Dc) (1967) }\end{array}$ & $\begin{array}{c}\text { Nei } \\
\text { (DA) (1983) }\end{array}$ \\
\hline PAT-NOA & 0.279 & 0.120 & 0.347 & 0.164 \\
\hline
\end{tabular}

Todas las estimaciones coinciden en mostrar diferenciación genética entre las poblaciones de los dos orígenes, situación que se confirma al utilizar el programa Structure (Pitchard et al., 2000), para realizar la asignación de individuos a clúster, en función de su parecido genético suponiendo que las frecuencias génicas están correlacionadas y que las poblaciones en estudio están mezcladas. Para cada valor de $\mathrm{K}$ (número de poblaciones) se realizaron tres corridas independientes. En $\mathrm{K}=2$, el NOA y el PAT se diferencian prácticamente en su totalidad con solo un $3 \%$ de individuos mezclados. En $\mathrm{K}=3$ los individuos PAT se ubican mayoritariamente en el clúster 2 (o.937), mientras que los del NOA comparten proporciones similares en el clúster $1(0.513)$ y en el 3 (o.463) mostrando que persiste la diferenciación respecto de PAT pero al mismo tiempo mayor dispersión genética. En $\mathrm{K}=4$, se acentúa la dispersión de los individuos del NOA que aparecen mayoritariamente en los clústeres 1 (0.423), 2 (0.27) y 3 (o.286), mientras que los individuos PAT se concentran en el clúster 2 (o.915) como se observa en el Cuadro 2 y se ilustra en la figura 1, donde cada barra indica un individuo y cada clúster tiene un color distinto.

Cuadro 2. Asignación de individuos clúster.

\begin{tabular}{lccccccccc}
\hline & \multicolumn{2}{c}{$\mathrm{K}=\mathbf{2}$} & \multicolumn{6}{c}{$\mathrm{K}=3$} & \multicolumn{6}{c}{$\mathrm{K}=4$} \\
\hline & 1 & 2 & 1 & 2 & 3 & 1 & 2 & 3 & 4 \\
\hline PAT & 0.03 & 0.97 & 0.021 & 0.937 & 0.042 & 0.017 & 0.915 & 0.034 & 0.034 \\
NOA & 0.976 & 0.024 & 0.513 & 0.024 & 0.463 & 0.423 & 0.021 & 0.27 & 0.286 \\
\hline
\end{tabular}

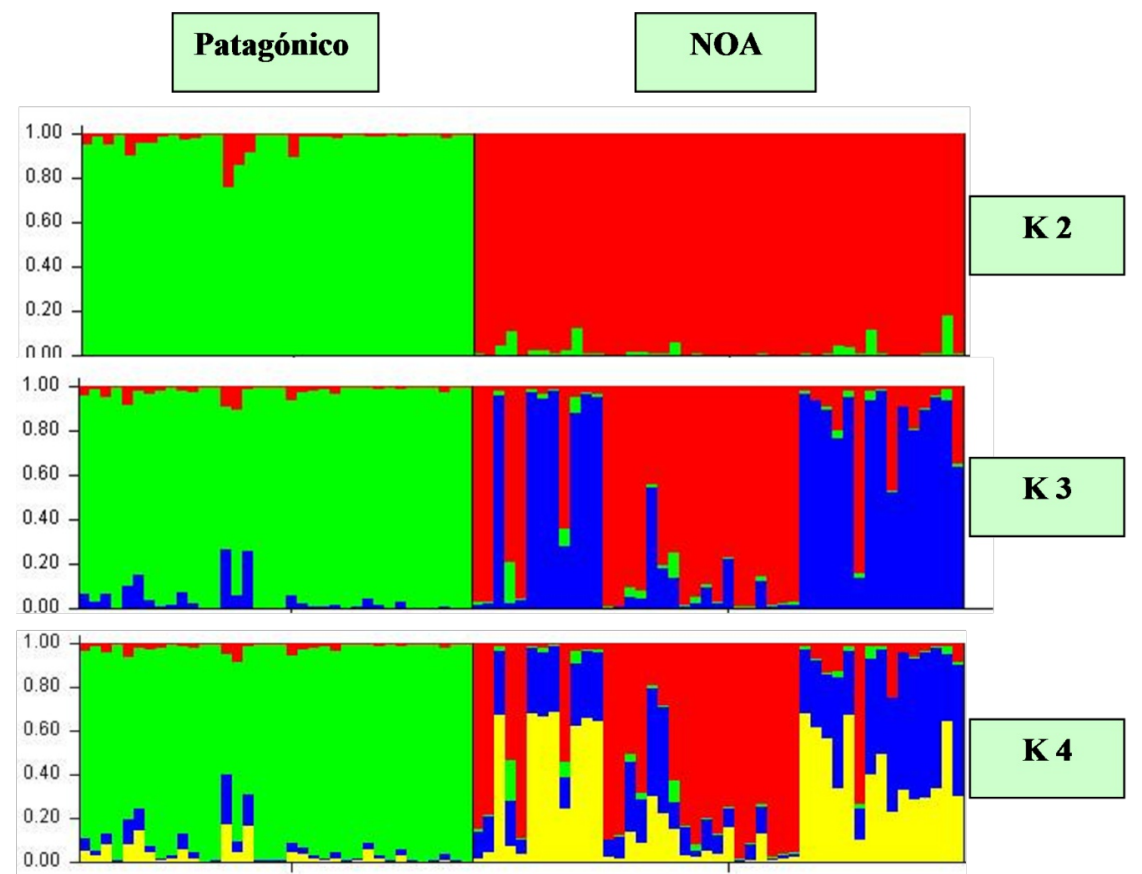

Figura 1. Asignación individual a Cluster para PAT y para NOA

\section{Marcadores genéticos moleculares para la terneza de la carne}

Entre todos los atributos que contribuyen a la calidad de la carne bovina, se ha comprobado que la terneza es el más apreciado por los consumidores (Teira, 2004). Esta valoración de la terneza le otorga a este atributo una gran importancia como objetivo de selección de reproductores en los rodeos bovinos (Guitou y Herrmann, 2010). Entre las razones que explican los cambios asociados a la terneza de la carne, se ha determinado como responsable al sistema proteolítico de las enzimas Calpaínas (CAPN1) y Calpastatinas (CAST), el cual actúa en la degradación post-mortem 
de las proteínas estructurales del músculo (ParraBracamonte et al., 2009). Se ha identificado en los genes que determinan la información para estas dos enzimas, algunas variantes polimórficas de un solo nucleótido (SNPs) que están asociadas a mayor o menor terneza: CAPN1 316 (variante $\mathrm{C}=$ favorable $\mathrm{y}$ $\mathrm{G}=$ desfavorable); CAPN1 530 (variante $\mathrm{G}=$ favorable y $\mathrm{A}=$ desfavorable) (Page et al. 2004) y CAST 2959 (variante $\mathrm{A}=$ favorable y $\mathrm{G}=$ desfavorable) (Casas et al. 2006). En el laboratorio de biotecnología molecular de la FCA UNLZ, se obtuvieron los genotipos de ciento cincuenta y cuatro (154) bovinos criollos para estos tres SNPs: Treinta y siete (37) correspondientes a animales de INTA Leales provincia de Tucumán (LE), cuarenta y uno (41) pertenecientes al INTA Chamical provincia de La Rioja (LR), cuarenta (40) pertenecientes al establecimiento Cruz de Guerra ubicado en 25 de Mayo provincia de Buenos Aires (CG) y treinta y seis (36) pertenecientes a la FCA UNLZ de origen patagónico (PA). A continuación, se observan los resultados obtenidos (Estevez et al. 2019). Las frecuencias genotípicas medias para los tres marcadores estudiados (Cuadro 3), registraron una alta proporción de individuos heterocigotos para los tres marcadores, destacándose por esta particularidad el CAST 2959.

Cuadro 3. Frecuencias genotípicas para los tres SNPs, en las cuatro poblaciones

\begin{tabular}{lccccccccc}
\hline & \multicolumn{1}{c}{ Frecuencias Genotípicas } \\
& \multicolumn{3}{c}{ CAPN1 316 } & \multicolumn{3}{c}{ CAPN1 530 } & \multicolumn{3}{c}{ CAST 2959 } \\
\hline & CC & CG & GG & GG & GA & AA & AA & AG & GG \\
\hline LR & 0.390 & 0.536 & 0.074 & 0.103 & 0.538 & 0.359 & 0.050 & 0.830 & 0.120 \\
CG & 0.230 & 0.642 & 0.128 & 0.154 & 0.564 & 0.282 & 0.000 & 0.846 & 0.154 \\
LE & 0.057 & 0.457 & 0.486 & 0.082 & 0.513 & 0.405 & 0.190 & 0.756 & 0.054 \\
PA & 0.333 & 0.389 & 0.278 & 0.139 & 0.444 & 0.417 & 0.139 & 0.722 & 0.139 \\
Media & 0.253 & 0.506 & 0.242 & 0.120 & 0.515 & 0.363 & 0.095 & 0.789 & 0.117 \\
\hline LR = La Rioja; CG = Cruz de Guerra; LE = Leales; PA = Patagónico.
\end{tabular}

Se registraron en total 29 genotipos diferentes considerando la combinación de los tres marcadores: CAPN1 316; CAPN1 530 y CAST 2959. En el Cuadro 4, se observan los genotipos combinados más frecuentes y su incidencia en cada una de las poblaciones

estudiadas, observándose heterogeneidad entre las cuatro poblaciones. El genotipo combinado más frecuente fue el CGGAAG $(n=32)$, heterocigota en los tres locus y por lo tanto con tres alelos favorables y tres desfavorables para terneza.

Cuadro 4. Genotipos combinados más frecuentes en el total de los individuos y su incidencia en cada población estudiada.

\begin{tabular}{cccccc}
\hline $\begin{array}{c}\text { Genotipos combinados } \\
\text { CAPN1 316/530/CAST 2959 }\end{array}$ & Total & LR & CG & LE & PA \\
\hline CGGAAG & 32 & 7 & 15 & 5 & 5 \\
CGAAAG & 18 & 8 & 2 & 7 & 1 \\
CCAAAG & 17 & 4 & 9 & 1 & 3 \\
GGAAAG & 12 & o & o & 7 & 5 \\
\hline
\end{tabular}

LR = La Rioja; CG = Cruz de Guerra; LE = Leales; PA = Patagónico.

En el Cuadro 5, se muestran las frecuencias alélicas registradas para los tres marcadores en las cuatro poblaciones, observándose diferencias principalmente entre los animales de LE y LR.

Cuadro 5. Frecuencias alélicas para los tres SNPs, en las cuatro poblaciones

\begin{tabular}{lcccccc}
\hline \multicolumn{7}{c}{ Frecuencias Alélicas } \\
\hline & CAPN1 316 & \multicolumn{2}{c}{ CAPN1 530 } & \multicolumn{2}{c}{ CAST 2959 } \\
\hline LR & 0.659 & 0.342 & 0.628 & 0.372 & 0.463 & 0.537 \\
CG & 0.551 & 0.449 & 0.436 & 0.564 & 0.423 & 0.577 \\
LE & 0.286 & 0.714 & 0.338 & 0.662 & 0.568 & 0.432 \\
PA & 0.528 & 0.472 & 0.361 & 0.639 & 0.500 & 0.500 \\
\hline Media & 0.506 & 0.494 & 0.441 & 0.559 & 0.489 & 0.511 \\
\hline LR = La Rioja; CG = Cruz de Guerra; LE = Leales; PA = Patagónico.
\end{tabular}

La raza Aberdeen Angus de Argentina presentó las siguientes frecuencias para los alelos de CAPN1 316: C = 0,292 y $\mathrm{G}=0,708$ y para CAST 2959: $\mathrm{A}=0,916$ y $\mathrm{G}=$ o,o84 (Guitou et al. 2011). Como puede observarse las frecuencias de las variantes alélicas favorables de los dos SNPs, son complementarias para las dos razas, C es alta en Criollo y baja en A. Angus y A es muy alta en A. Angus y media en Criollo. Al mismo tiempo la CAPN1 316 actúa favoreciendo la tiernización de la carne y la CAST 2959 inhibiendo a la CAPN1, por lo cual la combinación de las frecuencias de las dos razas equilibra las frecuencias de las variantes favorables a la terneza produciendo efectos beneficiosos en las poblaciones cruza, ya que en promedio los animales cruza, por ejemplo entre Aberdeen Angus (AA) y Criollo Patagónico (CP) o su recíproco, presentarán mayor frecuencia de genotipos favorables a la terneza de la carne que las dos razas puras, como se observa en las Cuadros 6, 7 y 8: 
Cuadro 6. Cruza AA x CP en CAPN1 316.

\begin{tabular}{lccc}
\hline \multicolumn{3}{c}{ CAST 2959 } \\
\hline \multirow{4}{*}{ Criollo Patagónico } \\
Angus & A: 0.916 & A: 0.5 & G: 0.5 \\
& G: 0.084 & 0.458 & 0.458 \\
& & 0.042 & 0.042 \\
\hline
\end{tabular}

Cuadro 7. Cruza AA x CP en CAPN1 316

\begin{tabular}{ccccc}
\hline \multicolumn{4}{c}{ CAPNI 316 } \\
\hline \multirow{4}{*}{ Angus } & & \multicolumn{3}{c}{ Criollo Patagónico } \\
& & A: 0.292 & 0.528 & G: 0.472 \\
& G: 0.708 & 0.1541 & 0.1378 \\
\hline
\end{tabular}

Cuadro 8: Cruza AA x CP Frecuencias genotípicas y génicas en marcadores de terneza

\begin{tabular}{|c|c|c|c|c|c|c|}
\hline & & \multicolumn{2}{|l|}{ CAPN1 316} & \multicolumn{3}{|c|}{ CAST 2959} \\
\hline & & $\mathrm{CC} \quad \mathrm{CG}$ & GG & $\mathrm{AA}$ & AG & GG \\
\hline \multirow{3}{*}{\multicolumn{2}{|c|}{$\begin{array}{l}\text { Angus } \\
\text { Criollo Patagónico } \\
\text { Cruza }\end{array}$}} & $0.085 \quad 0.413$ & 0.501 & 0.839 & 0.153 & 0.007 \\
\hline & & 0.3330 .389 & $0.278 \quad 0$ & 0.139 & 0.722 & 0.139 \\
\hline & & 0.15410 .5108 & 0.33410 & 0.458 & 0.500 & 0.042 \\
\hline \multicolumn{7}{|c|}{ Alelos Favorables a la Terneza } \\
\hline & Genotipo & Angus Criollo & Patagónic & & Cruza & \\
\hline \multirow[t]{2}{*}{ CAPN1 316} & $\mathrm{CC}$ & ----- & 66 & & 30 & \\
\hline & CG & 41 & 39 & & 51 & \\
\hline \multicolumn{2}{|l|}{ Total } & 41 & 105 & & 81 & \\
\hline \multirow[t]{2}{*}{ CAST 2959} & $\mathrm{AA}$ & 166 & 26 & & 90 & \\
\hline & AG & 15 & 72 & & 50 & \\
\hline \multicolumn{2}{|l|}{ Total } & 181 & 98 & & 140 & \\
\hline \multicolumn{2}{|c|}{ Total General } & 222 & 203 & & 221 & \\
\hline
\end{tabular}

Es interesante observar en el Cuadro 8, el efecto beneficioso de la cruza para la terneza de la carne, ya que, si bien Angus tiene muy alta frecuencia de variantes $\mathrm{A}$, favorables para la no inhibición de las Calpaínas, al tener baja frecuencia de variantes $\mathrm{C}$ de Calpaína favorable a la tiernización, no podrán ejercer su efecto beneficioso. En la cruza este efecto se ve contrarrestado por el alto aporte de variantes $C$
Calpaína favorable procedente de la raza Criolla. Se realizó un análisis factorial de correspondencias múltiples (figura 2), utilizando como variable clasificatoria los genotipos para los tres SNPs de los 154 animales analizados, con el objetivo de observar la agrupación de los individuos según su semejanza genética.

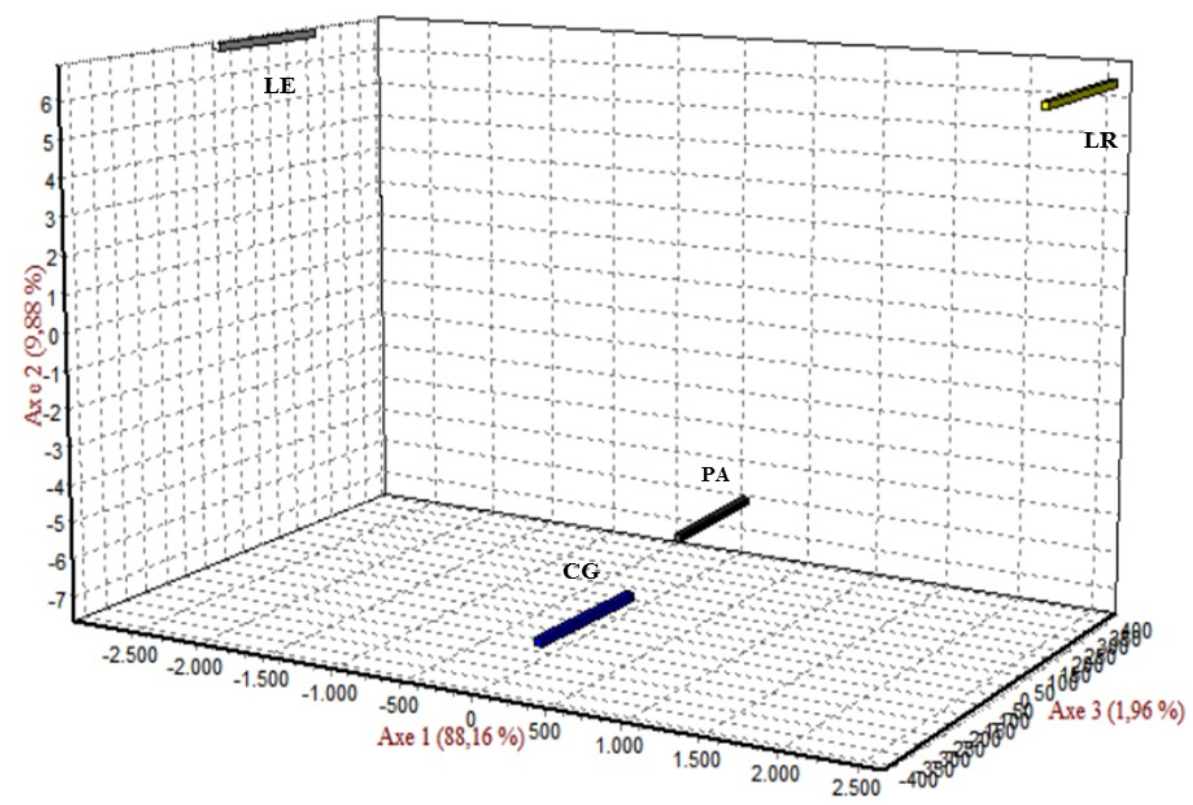

Figura 2. Representación gráfica del Análisis factorial de correspondencias múltiples. 
El primer eje factorial explicó el 88.16 \% de la variación total y el segundo eje un $10 \%$. En el gráfico se observan los centros de gravedad del conjunto de individuos de cada población. El primer eje factorial diferencia claramente las poblaciones de LE y LR ubicándolas en sectores opuestos, mientras que a las poblaciones de CG y PA las coloca en el mismo sector. El segundo eje factorial divide por un lado a LE y LR y por otro a CG y PA.

\section{El bovino Criollo en las provincias patagónicas}

\section{Provincia de Santa Cruz}

El desarrollo de la ganadería bovina puede verificarse mediante los datos de los censos oficiales de la provincia, que dan cuenta de un sostenido incremento del número de bovinos hasta 1914: $(1884=963 ; 1895$ $=11.000$ y $1914=44.000$ bovinos). Además de ser una de las principales fuentes de alimentos, el vacuno era por entonces un elemento fundamental para el transporte de cargas (lana, madera, etc.), que se realizaba en carretones tirados por bueyes. Estos bovinos eran de raza criolla, las razas británicas recién estaban ingresando en la pampa húmeda. De 1914 en adelante comienza otra etapa donde ocurren dos cosas: 1) Disminuye el número de bovinos en la provincia y 2) Comienza a cambiar la composición racial. La disminución del número obedeció principalmente a dos causas; la generalización del transporte de cargas por medios mecánicos y a que Punta Arenas pierde su hegemonía comercial (Lafuente H. 1981). El cambio de la composición racial se fue produciendo lentamente a partir de la paulatina introducción de animales de razas británicas (principalmente Hereford). De esta manera, los bovinos criollos puros en la provincia fueron disminuyendo paulatinamente hasta casi desaparecer de los rodeos comerciales (digo casi, porque la experiencia indica que siempre hay ganaderos que no hacen lo que hace la mayoría). A pesar de esta situación general, una población de bovinos criollos se mantuvo asilvestrada en estado de pureza racial en el sudoeste de la provincia, en el Parque Nacional Los Glaciares (figura 4). De los animales ubicados en Bahía Onelli norte y sur se extrajo el material genético fundador de los planteles que en la actualidad se encuentran en las localidades de Lago Argentino, chacra 9 de Julio de Horacio Echeverría (figura 3) y en la provincia de Buenos Aires propiedad de la Facultad de Ciencias Agrarias de la UNLZ. A la chacra 9 de Julio llegaron los primeros ejemplares en los años 1991 y 1992, desde entonces se crían ininterrumpidamente vacas criollas, han pasado años climáticamente muy duros, pero siempre se preñan y sobreviven a las condiciones más difíciles. Son muy longevas, mucho más que las Hereford que también existen en la Chacra y que suelen cruzarse con toros criollos para obtener terneros cruza que no requieren asistencia al parto, tienen mejor salud en general $\mathrm{y}$ presentan muy buen crecimiento $\mathrm{y}$ desarrollo. En esta chacra el manejo es complejo y requiere de hacer una etapa de invernada y otra de veranada. La veranada se hace en "el puesto" en zona de precordillera en el límite con Chile y la invernada abajo, en la chacra. Hay años en los cuales no es posible bajar todas las vacas al campo de invernada y algunas se quedan arriba en la montaña, donde solo habrá nieve para pasar el invierno y lo llamativo es que ellas se mantienen allí, en esas condiciones hasta el verano siguiente cuando vuelven a unirse al rodeo general.

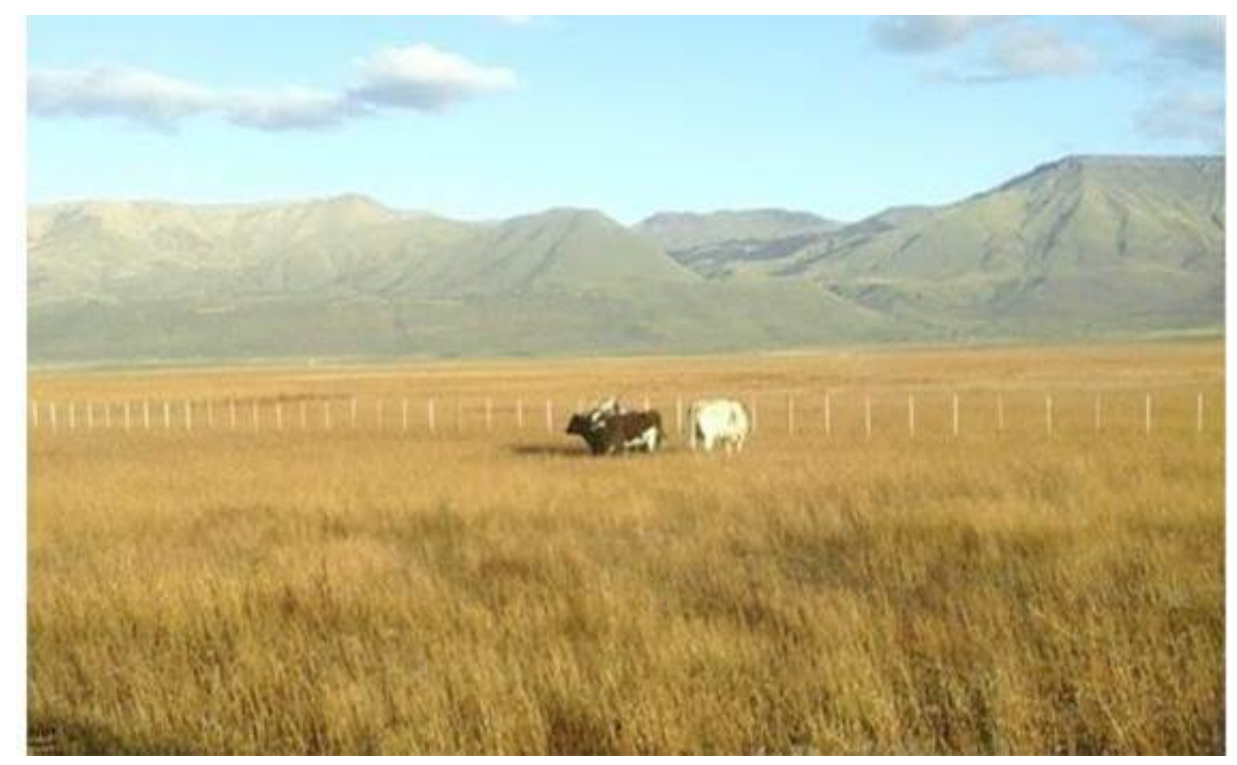

Figura 3. Chacra 9 de Julio, Lago Argentino, provincia de Santa Cruz. Vacas Criollas (2017) 


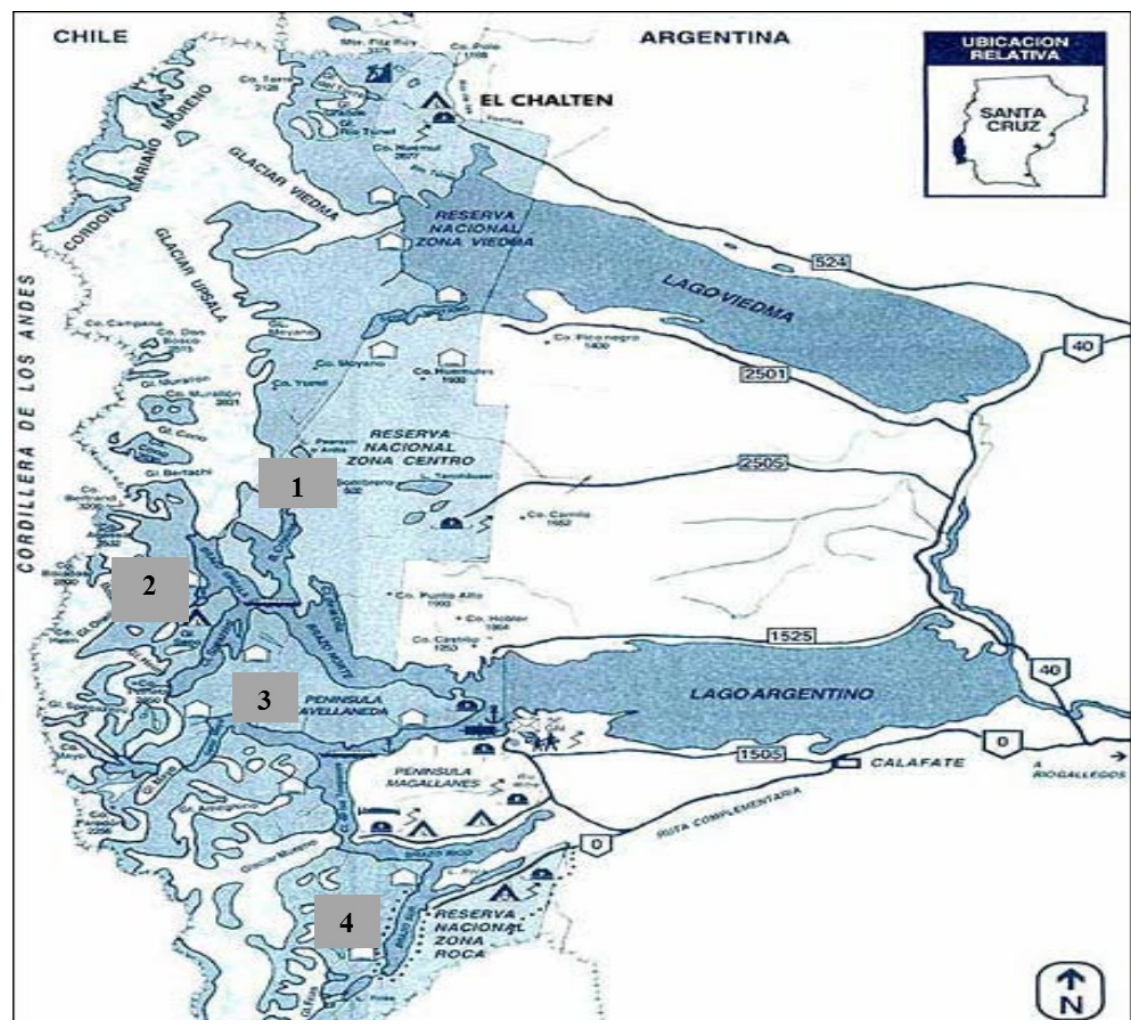

Figura 4. Parque Nacional Los Glaciares: Presencia de bovinos criollos: 1. Estancia Cristina. 2. Bahía Onelli norte y sur. 3. Península Avellaneda. 4 La Aurelia.

\section{Provincia de Chubut}

Las primeras vacas que arribaron en forma oficial a la provincia, lo hicieron el 7 de octubre de 1783 , cuando los españoles fundaron la estancia El Rey sobre el golfo San Jorge en la Península de Valdez, llevando 9 vacas, 36 novillos y bueyes (Bavera G 2011), pero el mayor desarrollo ganadero recién comenzó con la llegada de la colonización galesa en 1865. En el informe que realizaron Lewis Jones y el capitán Love Jones Percy, luego de su visita de reconocimiento de la región expresan "el lado norte del río Chubut es mejor que el lado sur, el pasto en el valle, llega en algunos casos a la altura de los hombros. Hay miles de vacas con sus crías al pie y grandes rebaños de ovejas rojas". El vacuno criollo fue un acompañante permanente en la vida de los colonos galeses, se utilizó como animal de trabajo, como productor de carne y como productor de leche, que además de su consumo en fresco, se utilizaba para su industrialización, fabricando manteca y queso. En 1880 la Colonia de Chubut había logrado fundar los pueblos de Puerto Madryn, Gaiman, Rawson y Trelew y su producción ganadera y agrícola era cada vez mayor. En 1886 llegaron a colonizar el oeste provincial, en la actual ciudad de Trevelin, bautizada entonces como Colonia 16 de Octubre, donde las tierras y el clima es mucho mejor para la actividad agropecuaria, lo cual contribuyó a su rápido crecimiento y en 1895 contaban con 48741 bovinos criollos (Martínez R 2001). En esa misma localidad en el año 1890 inicia sus actividades la estancia y cabaña El Parque con vacas criollas, en 1905 comienza a cruzar las vacas originales con toros Hereford puros traídos directamente de Inglaterra para obtener Hereford puros por cruza. Así cuenta don Kenneth Berwyn propietario del establecimiento quien en 1992 decide retomar la cría de bovinos criollos buscando algunos ejemplares que todavía existían en la zona en la colonia Cushamen. Esas vacas fueron inseminadas con semen del toro Don Segundo, primer campeón en la exposición de Palermo y las primeras crías nacieron en el año 1994. Luego se utilizó semen de otro toro del norte, Atilio y en el año 2004 se sometió el rodeo a consideración de la AACGBC en la persona de Don Martín Garciarena y a partir de ese momento se inscribió el plantel en el registro genealógico de SRA asignándole el número 43. Actualmente el plantel cuenta con cuarenta vacas adultas con un peso promedio de $480 \mathrm{~kg}$. y los toros marcan diferencias con otras razas por su actitud de liderazgo y guardianes del rodeo. En el año 2003, cerca de Trevelin, en la localidad de Cholila, el médico veterinario Marcelo Aceval y su señora Débora Finkelstein en un predio familiar, donde tenían un plantel de vacas Hereford de pedigree, comenzaron a armar un rodeo de madres criollas para revertir la ineficiencia productiva que se observaba en ese momento, poniendo vacas eficientes y adaptadas al ambiente cordillerano y de meseta. Compra vacas criollas o "acriolladas" de distintos sectores, algunas 
que se encontraban asilvestradas en el Parque Nacional Los Alerces en la zona de Población Burgos, en Lago Rivadavia, otras a un criador de la meseta en la zona de Rinconada y otras provenientes de El Calafate provincia de Santa Cruz a un empresario dedicado al engorde de vacunos de la localidad de Gaiman provincia de Chubut. A estas vacas, las inseminó con semen de cuatro toros criollos patagónicos, comprado a la Facultad de Ciencias Agrarias de la UNLZ. El resultado de este cambio ha sido excelente, se ha incrementado el porcentaje de destete de un 50 \% que tenía con las vacas anteriores, a un $80 \%$ con las criollas, además de disminuir considerablemente los costos de suplementación invernal y de sanidad. Otro tema fundamental que se ha resuelto es que los problemas al parto que antes eran frecuentes, ahora no existen. En el año 2014, la Estancia Numancia situada en Aldea Beleiro (cordillera, límite con Chile), adquirió dos toros Criollos de la Cabaña el Parque de Trevelin, uno de 3 años y un ternero, con el objetivo de repasar las vaquillonas Hereford diente de leche para lograr facilidad de parto. Luego de esto, la estancia adquiere el campo Chali Aique en la zona de sierras y mesetas (200 mm de precipitación anual) que requiere la intervención de ganado mayor para lograr mejoras en el pastizal y en ese contexto se decide llevar a ese campo todas las F1 hembras nacidas en Numancia, más las hembras Hereford descartadas por el inspector de la Asociación. Las hembras se recrían allí y entran en servicio con toros A. Angus y Criollos. En el año 2018 se comienzan a hacer algunas mediciones reproductivas del rodeo de Chali Aique, donde se observó que las cruzas Criollas $(1 / 2 \mathrm{C}-1 / 2 \mathrm{H})$ y $(3 / 4 \mathrm{C}$ - 1/4 H) superaron a las Hereford puras tanto en el porcentaje de preñez como en su condición corporal (87 \% y 2.5) vs. (77.5 y 2.3). Se destaca el comportamiento de los toros criollos por su buena presencia y la defensa de su harén. Hay anécdotas donde toros Hereford saltaron el alambre y el Criollo no los dejo acercarse al rodeo. También son muy caminadores, andan dos leguas para "robarse" la vaca lechera de la estancia. En el año 2018, se adquirió una jaula de criollos asilvestrados provenientes de Península Avellaneda, Parque Nacional Los Glaciares, provincia de Santa Cruz, de allí llegaron vacas y terneros, con el objetivo de continuar con el aprovisionamiento de toros criollos puros. Alejandro Correa, médico veterinario radicado en el Valle de Sarmiento, explica que la incorporación de genética criolla al rodeo provincial va a generar animales que puedan trasladarse en busca de alimento, muchas veces en campos con terreno pedregoso, con pendientes y con grandes extensiones, como por ejemplo con 3-4 leguas de superficie (1 Legua: 2,500 hectáreas). También que se puedan reproducir en espacios agrestes con alimentos muy fibrosos, soportar el impacto de la radiación solar durante varias horas en época estival; así como también fríos, heladas y nieve en invierno. Asimismo, por el contexto donde se han desarrollado sus ancestros, suponemos que puedan soportar la presencia de depredadores como el puma, y competidores de recursos como el Guanaco (fauna autóctona). El objetivo de la reincorporación de esta raza en Chubut es producir carne de alta calidad en superficies hoy improductivas o subproductivas; diversificar la producción en otros casos y con ello los ingresos de los productores. Lograr formar rodeos de madres rústicas, fértiles y con tamaños adultos moderados, acordes a posibles limitaciones forrajeras. Además, se buscan corregir defectos de rodeos comerciales, como es el caso de predisposición a cáncer de ojo (carcinoma espinocelular), partos distócicos y otros defectos inherentes a la habilidad materna.

\section{Provincia de Río Negro}

El origen y desarrollo de la ganadería rionegrina, se debió al intercambio que se entabló con los indios, quienes a cambio de aguardiente y efectos abastecieron de caballos, vacunos, ovejas y mulas al establecimiento fundado por Francisco de Viedma (Gorla 1983). Estas acciones tuvieron lugar a fines del siglo XVIII y principios del XIX, cuando los únicos bovinos presentes en la región eran los criollos. Según cifras oficiales en 1888 existían en Río Negro 102.894 cabezas de bovinos, en 1890, 400.000 cabezas y en 1894 ascendían a 500.000 cabezas (Ruffini M. 2003). Como ha ocurrido en la zona pampeana, también aquí el bovino criollo fue mestizado con razas británicas principalmente Hereford y A. Angus y en la actualidad no existe un relevamiento racial bovino que permita identificar de forma precisa el número y la ubicación de los bovinos criollos existentes en la provincia, por lo cual lo más habitual es desconocer su existencia. Felizmente para la ganadería rionegrina en el año 2018, Lisandro Ruiz Moreno un emprendedor ganadero logró concretar su proyecto de establecer en plena estepa patagónica en la localidad de Sierra Grande un establecimiento productor de carne bovina teniendo como base a la raza bovina criolla, he aquí el relato de su experiencia: 
"En la Patagonia, la geografía y su diversidad de ambientes cambian constantemente del mar a la cordillera y viceversa, dando vida a una variada flora y fauna. Busque en la estepa patagónica, donde los campos son duros,llueve muy poco (150 mm anuales en promedio) a diferencia de los campos de precordillera o incluso cordillera donde el régimen de lluvia es abundante y las veraneadas son ricas en proteínas y pastos verdes por todos lados. Estudiando y buscando una raza bovina que se adapte a este ambiente poco amigable para la fauna no autóctona, encontré a la Raza Criolla, pensando siempre primero en el ambiente y luego en la genética que podía implantar en ese lugar. Al elegir esta raza bovina, tuve en cuenta su historia y estudios realizados, pero fundamentalmente su rusticidad y facilidad de parto. La rusticidad es fundamental para vivir en el lugar donde está ubicado el establecimiento. La facilidad de parto, no solo por la falta de instalaciones y apotreramiento de los campos, donde los lotes son grandes o muy grandes y no es posible estar encima de las vacas todo el tiempo, sino también porque se facilita el manejo y se disminuyen los costos. En relación a su mansedumbre, que es otra de las características del Criollo, no le di importancia o la pasé por alto, además, sabiendo que las vacas que podía conseguir estaban asilvestradas desde varias generaciones, pensé que esto iba a ser imposible, que se iban a comportar como cualquier animal salvaje y su mansedumbre se iba a manifestar recién en las nuevas generaciones nacidas en mi establecimiento. Por fortuna, coincidió que mientras estaba poniendo a punto mi establecimiento, una empresa comenzó a extraer animales criollos de Península Avellaneda en el Parque Los Glaciares, provincia de Santa Cruz. La captura y extracción de los animales en esa inmensa geografía, implica una serie de trabajos y acciones complejas y costosas. Se trasladan en barco hasta el puerto de Punta Bandera, donde se alojan en corrales, para luego desde ahí ser trasladadas a su destino final. Todo el proceso hasta juntar una jaula de animales en Puerto Bandera, puede tardar más de un mes, por lo cual se genera una importante pérdida de estado corporal y estrés en los animales. Por último, las criollas se cargaron en camiones que recorrieron 1600 kilómetros para llegar a mi establecimiento (El Manantial), ubicado en la localidad de Sierra Grande provincia de Rio Negro (figura 5). Los camiones fueron tres, el primero llegó el 4 de julio de 2018, el segundo el 13 de julio del mismo año y el último el 22 de febrero de 2019. Llegaron en un estado crítico (cada jaula traía cuatro a cinco vacas caídas en el piso), donde les esperaba un ambiente no conocido (muy diferente al de su origen). Ahí es donde me pregunté y puse en duda su capacidad de adaptación al ambiente y su rusticidad. La mansedumbre la pasé por alto nuevamente en ese momento, porque principalmente necesitaba que las vacas se adaptasen y pudieran sobrevivir a todo lo que fueron expuestas hasta llegar a su destino final y comenzar su nueva odisea, que era adaptarse a otra flora y condiciones ambientales muy diferentes de donde se criaron. Vinieron vacas de todas las edades, novillos (fueron capados una vez capturados), y terneras de muy corta edad sin su madre, es decir que cargaron el camión "al barrer". Las dejamos unos días en los corrales con agua y pasto para que se repongan y antes de largarlas al campo, a las vacas se les realizó diagnóstico de preñez (para sorpresa nuestra el $90 \%$ estaban preñadas). Esta situación nos generó preocupación debido al estado corporal y a tener que gestar un ternero después del estrés ocasionado y a su nueva adaptación. Pero las vacas estaban ahí, y las largamos al campo para continuar su ciclo biológico y poner a prueba las características por las cuales las busqué, que fueron principalmente las dos que mencioné anteriormente, su rusticidad y facilidad de parto (dejando por supuesto nuevamente para otra generación su mansedumbre).

\section{Rusticidad}

Las vacas empezaron a caminar siempre en fila india y en distintos grupos, por todo el campo, buscando quien sabe qué, respetando los alambrados como si los conocieran y más aún, respetando los boyeros de un solo hilo, como nunca vi en otra raza. Fueron mejorando su condición corporal muy significativamente, las vacas caminan mucho para buscar los mejores pastos (los pocos que hay) y siempre están en constante movimiento. Las dejamos un tiempo sin molestarlas, solo recorrimos los lotes para ver que no salten alambrados y no rompan los bolleros, cosa que nunca sucedió. Después de 40 o 45 días, las encerramos, no fue fácil por la amplitud del lote y la geografía con muchas sierras y quebradas, pero encerramos la totalidad en el curso de una semana y así lo hicimos aproximadamente cada 60 días. Me llamó la atención que cuando juntábamos un grupo y lo encerrábamos en un potrero de veinte hectáreas aproximadamente (mientras juntábamos las demás), las vacas se comían hasta la jarilla, cuando no quedaba otra cosa. Tienen ese "gen" de sobrevivir como sea y donde sea. Parecen argentinos, que a pesar de todos los males siempre salimos adelante (apreciación personal). Los novillos, enseguida mejoraron y engordaron con mucha facilidad, eso me llamo profundamente la atención, porque no hay pastos verdes o en raras ocasiones en primavera aparece algún pasto verde y muy poco nutritivo. Eran ocho novillos y los vendimos como gordos.

\section{Facilidad de Parto}

Las vacas que vinieron preñadas parieron todas, solo una que mal parió, su estado corporal era realmente complicado (venía echada en el camión, esta misma vaca se recuperó y hoy tiene un ternero al pie) y hasta ahora no tuvimos ninguna vaca con problemas de distocia. Criaron su ternero a campo sin ninguna suplementación. Tienen la costumbre cuando el ternero es chico (entre 1 y 15 días de vida), de 
vida), de dejarlo en el campo cuando se las encierra y después cuando se la larga salen disparando en busca de su ternero. Son lotes grandes de tres mil y cinco mil hectáreas de monte bajo. Pero lo encuentran enseguida y el ternero no se mueve de donde la vaca lo deja. Los porcentajes de preñez y destete recién ahora nos estamos ocupando o armando las planillas, no lo hicimos antes para no molestar a la vaca, que venía con un gran estado de estrés y también por una cuestión de apotreramiento e instalaciones, que ahora nos estamos acomodando. Pero, por conocimiento de la gente que trabaja en el establecimiento y recorrer la hacienda y encerrar por distintos motivos (no son más de 120 vacas), estamos en un 85 por ciento de preñez y un 100 por ciento de destete, teniendo en cuenta que entre abril de 2019 y marzo de 2020 se registraron solo $40 \mathrm{~mm}$ de 1 luvias, los resultados productivos son extraordinarios.

\section{Mansedumbre}

$\mathrm{Al}$ principio nos costó encerrarlas, en el primero y segundo encierre. Una vez dentro de los corrales se comportaban normalmente, ninguna vaca intentó saltar el alambrado o

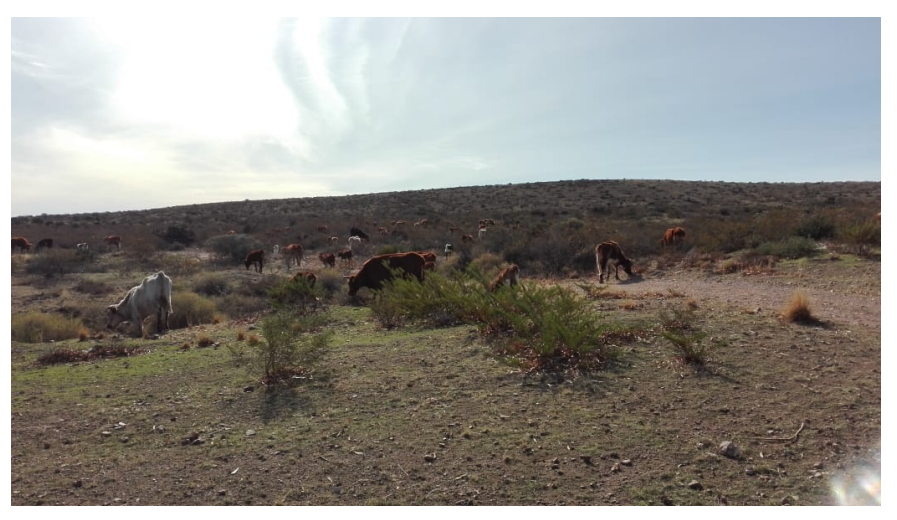

Figura 5. Campo El manantial. Vacas Criollas con sus terneros en la estepa patagónica (2019).

\section{Provincia de Tierra del Fuego}

Si bien la presencia de bovinos en Tierra del Fuego es anterior al siglo XIX, recién finalizando este siglo comienza el desarrollo ganadero de la provincia, con la fundación de la estancia "Harberton", cerca de la ciudad de Ushuaia y de la estancia "Primera Argentina”. Los primeros bovinos criollos se utilizaron para triple propósito: trabajo (bueyes), carne y leche para consumo local (Moreno et al., 2011). En 1917, se funda el frigorífico "Río Grande" perteneciente a la "Compañía Frigorífica Argentina de Tierra del Fuego", lo cual impulso la producción de carne bovina (Romero Aguirre, 1957). En 1956, llegan en barco los primeros bovinos de raza Hereford al campo "Remolino", propiedad de la Base Naval. Luego, en 1963/64 llegan por avión a la estancia María Behety, atropellar. A partir del tercer encierre las vacas ya sabían adónde tenían que ir y en fila india marchaban la mayoría y sin inconvenientes. Personalmente tuve que arrear cuatro vacas con sus terneros durante 10 kilómetros en un potrero con mucha sierra y quebradas, donde por momentos se pierde la visibilidad de las vacas, pero ellas sabían perfectamente donde tenían que ir. Las vacas más adultas puntean y las otras las siguen en fila india, esto facilita la tarea. Se arman grupos de entre ocho y diez vacas con sus crías. Mirando su forma de actuar le pusimos un cencerro a las vacas que siempre encabezan las filas. Hoy el encierre lo hace una sola persona, y en dos horas o tres, encierra casi toda la hacienda (145 a 170 vacas y sus crías), con mucha tranquilidad y sin inconvenientes. Esto en lotes planos o con pocas quebradas. En lotes de sierra se tarda más por una cuestión geográfica. Su mansedumbre y acostumbramiento es realmente llamativo, muy favorable al manejo en campos tan grandes.

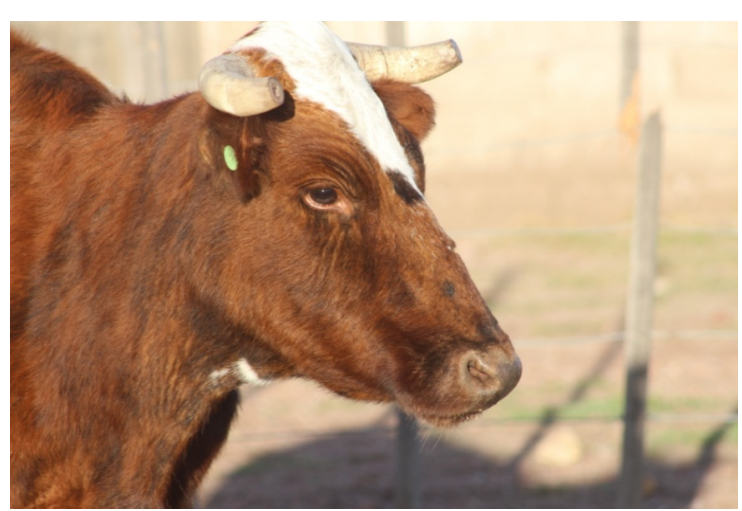

Figura 6. Vaca Criolla. Expresión de mansedumbre y sobriedad (2019).

unas 120 vaquillonas y toros. Al año siguiente llegaron toros PDP y PR. En diciembre de 1967 un brote de aftosa eliminó el 50\% de estos animales y el otro 50\% fue sometido a rifle sanitario, según la reglamentación internacional vigente. Con ello desapareció la raza Hereford, hasta 1972/73, cuando ingresaron 250 animales puros de pedigre (PDP) y puros registrados (PR) entre vaquillonas y toros (Moreno et al. 2011). Es decir que en esta provincia los cruzamientos de los bovinos criollos con razas británicas recién se establecieron en 1980. La evolución de las existencias bovinas provinciales, se observan en el Cuadro 9, donde podemos ver que el crecimiento en el número de bovinos se produjo a partir de la década del 80, fruto de la promulgación de la Ley de Promoción Económica y Fiscal $\mathrm{N}^{\circ} \mathbf{1 9 . 6 4 0}$ que favoreció la introducción de razas británicas. Actualmente, hay 
grupos de ganado criollo asilvestrado, pero las dos poblaciones más importantes se encuentran en la Península Mitre y en el Parque Provincial Corazón de la Isla. Ambas zonas, son extensas tierras públicas y de muy difícil acceso. En el área protegida de Corazón de la Isla existe ganado asilvestrado, aunque es común que algunos propietarios de campos linderos aprovechen el espacio con ganado propio. Por ejemplo, recientemente como resultado de un fallo judicial el Estado logró el retiro de unas 2.000 cabezas de ganado vacuno reclamadas por una estancia lindera (Carranza, Com pers., 2018). La Península Mitre, se caracteriza por la existencia de ganado criollo asilvestrado de varias generaciones, con una abundancia y densidad mucho más alta que en cualquier otro sitio de la isla. Tradicionalmente la forma de explotación de este ganado fue mediante la captura o "bagualeo". La Península Mitre es el extremo oriental de la Isla Grande, comprende casi 300.000 ha y representa el 14 $\%$ de su superficie. La región está definida por la predominancia de planicies onduladas y colinas de cimas redondeadas, cubiertas de vegetación. También se la denomina región de las turberas, por que presenta la mayor riqueza florística y predominancia de estos ecosistemas sobre cualquier otra formación vegetal, cubriendo más de la mitad de la superficie de la península. Es una zona inhóspita, con clima riguroso que determina que se encuentre prácticamente deshabitada. Esta particularidad hace que el ambiente natural y las especies que lo habitan se conserven en buen estado, por lo cual es un importante refugio para la fauna silvestre nativa. En el año 2014, a partir de una iniciativa de la Dirección General de Bosques de la provincia, se realizaron relevamientos sobre la presencia de bovinos criollos en el área de Península Mitre (Collado, 2015). Se hicieron conteos a través de censos de línea de transecta terrestres y también mediante sobrevuelos de helicóptero para estimar la cantidad de animales presentes en todo el sector de Península Mitre. Los resultados de este trabajo se observan en el Cuadro 10, destacándose la zona costera como la más densamente poblada, que se justifica si consideramos que la costa atlántica cuenta con pastizales de gramíneas, con inviernos suaves por su cercanía al mar. En el interior los recursos son escasos, la superficie está casi toda cubierta por turberas de juncáceas, musgos, astelia, y por áreas boscosas, donde los recursos forrajeros se limitan al bosque abierto, especialmente de lenga (Caducifolios) y a las riberas de los cursos de agua principales.

Cuadro 9. Evolución de las existencias bovinas en la provincia de Tierra del Fuego.

\begin{tabular}{lcllccccc}
\hline Año & 1908 & 1945 & 1960 & 1985 & 1995 & 1998 & 2008 & 2017 \\
Existencias & 11000 & 5500 & 5000 & 17000 & 28400 & 30000 & 41000 & 44000 \\
\hline
\end{tabular}

Cuadro 10. Relevamiento de la cantidad de animales censados en el sector de Península Mitre.

\begin{tabular}{lccccc}
\hline Zona & $\begin{array}{c}\text { Superficie } \\
\text { censada (ha) }\end{array}$ & $\begin{array}{c}\text { Superficie x zona } \\
\text { (ha) }\end{array}$ & $\begin{array}{c}\text { Animales } \\
\text { censados }\end{array}$ & $\begin{array}{c}\text { Estimación } \\
\text { animales x ha }\end{array}$ & $\begin{array}{c}\text { Animales } \\
\text { estimados x zona }\end{array}$ \\
\hline Costa & 2865 & 36330 & 775 & 0.11 & 3989 \\
Interior & 4220 & 273428 & 159 & 0.02 & 4195 \\
Total & 7085 & 309758 & 934 & 0.06 & 8184 \\
\hline
\end{tabular}

Según información de la Dirección de Desarrollo Agropecuario - SDSyA, la relación de sexos en el ganado vacuno asilvestrado en la Península Mitre (al menos en el sector costero), es de 1.5 a 2.5 machos por cada hembra. Es decir que existirían entre 5000 y 5 800 machos y entre 2300 y 3200 hembras. Solo en Península Mitre la presencia de bovinos criollos asilvestrados (figura 7), representa casi el $20 \%$ de las existencias bovinas provinciales. Es sin dudas un reservorio genético bovino de enorme valor zootécnico que podría tener un importante impacto en la mejora de la productividad ganadera provincial y de toda la región patagónica, mediante el aporte de genes y combinaciones de genes relacionados con la fertilidad, la rusticidad, la longevidad y todos aquellos atributos que requiere la especie bovina para desarrollarse en producciones extensivas con ambientes difíciles y cambiantes como ocurre en toda la región patagónica. 


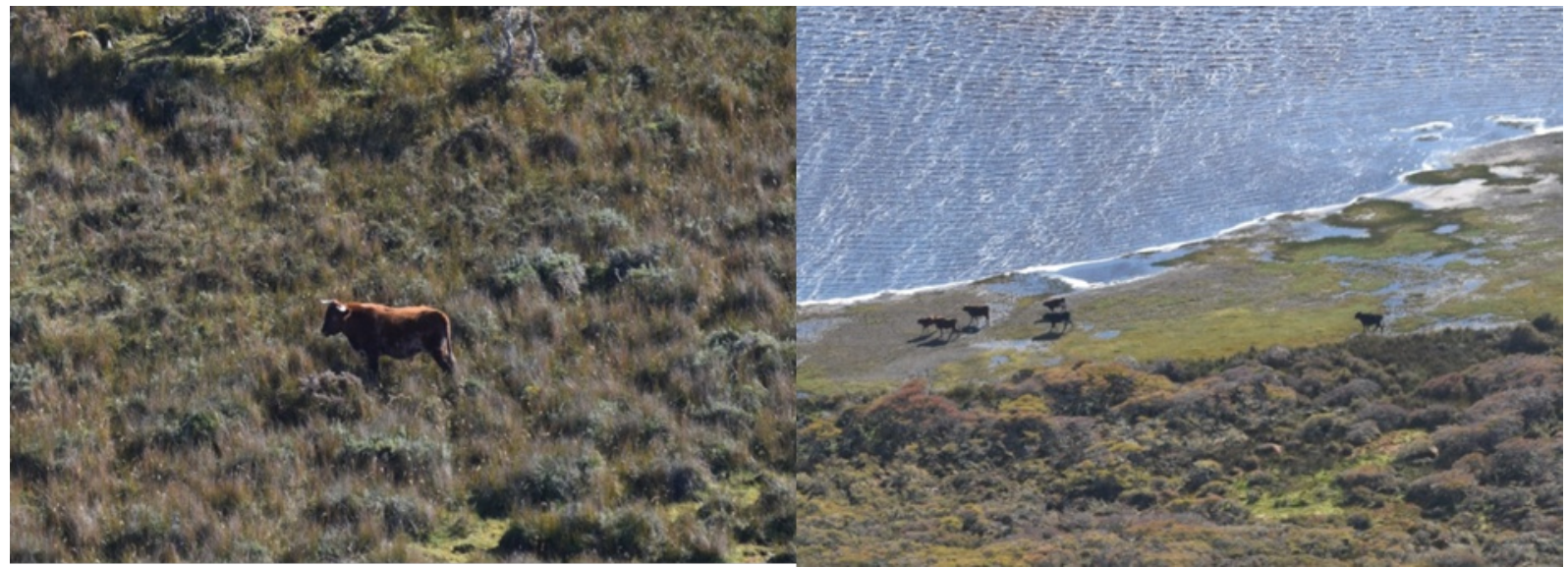

Figura 7. Bovinos Criollos asilvestrados. Zona costera de la Península Mitre. Provincia de Tierra del Fuego (2017).

\section{Conclusiones}

La Patagonia argentina, cuenta con un recurso genético bovino hecho a su medida. Particularmente en las circunstancias actuales, donde se observan bruscos cambios climáticos, se requieren bovinos con diversidad genética y diversidad de colores, que puedan evolucionar en relación al ambiente. La incorporación de bovinos criollos a los sistemas productivos comerciales de manera lógica, racional y ordenada puede mejorar la productividad y transformar la producción bovina de la región de manera sustancial.

\section{Reconocimientos}

A todos los productores de Argentina que valoran la diversidad genética y fenotípica de los bovinos independientemente de la raza, en especial al Dr. Sol. L Rabasa y a Miguel Solanet, ex presidentes de la AACGBC.

\section{Literatura Citada}

Bavera, G. 2011. Razas bovinas y Bufalinas de la Argentina. Editorial Imberti Bavera Primera edición.268 pp.

Bustos J. A. 1993. Indios y blancos, sal y ganado más allá de la frontera. Patagones 1820-1830. Anuario del IEHS. VIII Tandil provincia de Buenos Aires Argentina. Pág. 27-45.

Casas E., White S.N., Wheeler T.L., Shackelford S.D., Koohmaraie M., Riley D.G., Chase Jr C.C., Johnson D.D. \& Smith T.P.L. 2006. Effects of calpastatin and $\mu$-calpain markers in beef cattle on tenderness traits. J Anim Sci. 84:520-525.

Collado, L. 2015. Evaluación del estado ambiental y de uso por ganado asilvestrado de los distintos ambientes de la Península Mitre, con énfasis en los bosques. Cuantificación y análisis. Informe Técnico, Secretaría de Desarrollo Sustentable y Ambiente, Dirección General de Bosques. 147 pp.

De Alba Martínez, J. 2011. El libro de los bovinos criollos de América. Ediciones Papiro Omega S.A de C.V. México. 444 pp.
Ensminger, M.E. 1973. Producción bovina para carne. Editorial El Ateneo. Buenos. Aires. 595 pp.

Estévez D., Holgado F., Tessi J., Fernández E., Género E. y Martínez R. 2019. Estudio de frecuencias en marcadores de terneza en bovinos criollos argentinos. Revista AICA Nro. 14 73-79.

Falconer D S y Mackay T F C. 2001. Introducción a la Genética Cuantitativa. 4ta Edición. Editorial Acribia SA. 469 pp.

Giberti Horacio C E. 1970. Historia económica de la ganadería argentina. Ediciones Solar Hachete Buenos Aires primera reimpresión $211 \mathrm{pp}$.

Gorla C M. 1983. Origen y desarrollo de la ganadería patagónica $(1779$ - 1810). FECIC Fundación para la educación la ciencia y la cultura. $185 \mathrm{pp}$.

Gotta C. 1993. Una aproximación histórica al problema del ganado como moneda en norpatagonia, siglos XVIII-XIX. Anuario IEHS Nro. 8 Fac. Cs. Humanas U.N.C Tandil pág. 13-25. 
Guitou H. y Herrmann P. 2010. Marcadores Moleculares de Terneza: Calpaina y Calpastatina. Revista Angus Número 249 Pag.73-77.

Helman M. 1983. Ganadería Tropical. Tercera Edición. Editorial El Ateneo Buenos Aires.622 pp.

Helman M. 1986. Cebutecnia. Segunda Edición Editorial El Ateneo Buenos Aires.549 pp.

Inchausti y Tagle (1980); Bovinotecnia. 6ta. Edición. Editorial El Ateneo Buenos Aires Argentina. 800 pp.

Lafuente H. R. 1981. La Región de Los Cesares. Apuntes para una historia económica de Santa Cruz. Editorial de Belgrano.253 pp.

Lebedinsky M. 1967. "Estructura de la ganadería" Histórica y actual. Editorial Quipo Buenos Aires.161 pp.

Mareco G. 2013. Bovinos Criollos Argentinos Patagónicos (Bos taurus, Linneus, 1758) REDVET Revista Electrónica Volumen 14 Nro. 10. http://www.veterinaria.org/revistas/redvet

Martínez, R. 2001. Importancia del bovino criollo en la colonización galesa Revista Espacios. Año VII Nro 19. 58-61. Universidad Nacional de la Patagonia Austral.

Martínez, R. D. 2008. "Caracterización genética y morfológica del bovino criollo argentino de origen patagónico". Tesis doctoral publicada por el Departamento de Ciencia Animal de la Universidad Politécnica de Valencia España. 244 pp.

Montoya Alfredo Juan. 1984. Como evolucionó la ganadería en la época del virreinato. Editorial Plus Ultra Buenos Aires Argentina.391 pp.

Moreno, J.; Font, P. y Olmedo, E. 2011. Cadena de valor de la carne bovina en la provincia de Tierra del Fuego. Consejo Federal de Inversiones.72 pp. http://biblioteca.cfi.org.ar/wpcontent/uploads/sites/2/2016/o4/item-d_-tdf.pdf

Morrison C. 1917. La ganadería en la región de las mesetas australes del territorio de Sta. Cruz. Tesis Facultad de Agronomía y Veterinaria de Buenos Aires. 105 pp.

Moyano C. 1868. Carlos Moyano el explorador de la Patagonia. Editorial El Ateneo Buenos Aires.310 pp.

Page B. T., Casas E., Quaas R. L., Thallman R. M., Wheeler T. L., Shackelford S. D., Koohmaraie M., White S. N., Bennett G. L., Keele J. W., Dikeman M. E. \& Smith T. P. L. 2004. Association of markers in the bovine CAPN1 gene with meat tenderness in large crossbred populations that sample influential industry sires. J. Anim. Sci. 82:3474-3481

Palermo, M. A. 1988. "La innovación agropecuaria entre los indígenas pampeano-patagónicos, Génesis y Procesos. Anuario IEHS Univ. Nac. Del Centro Tandil Pcia. Bs. As. Pág. 43-90.
Parra-Bracamonte G., Sifuentes-Rincón A., ArellanoVera W., Almanza-Gonzalez A. y De La Rosa-Reyna $X$. 2009. Tipificación de tres marcadores genéticos de caracteres de importancia comercial en ganado Charolais: implicaciones en la ganadería para carne en México. Rev. Col. Cien. Pec.22: 257-266.

PROSAP. Programa de Servicios Agrícolas Provinciales. 2014. Estrategia Provincial para el Sector Agroalimentario. Ministerio de Industria e Innovación Productiva, Provincia de Tierra del Fuego, Antártida e Islas del Atlántico Sur.81 pp.

Rabasa A.E., Holgado F.D. y Poli M.A. 2005. Bovino Criollo de Argentina: Diferentes aspectos en su caracterización. Agrociencia. Vol. IX N ${ }^{\circ} 2 \mathrm{y} \mathrm{N}^{\circ} 3$ pág. $473-477$.

Rodríguez C A, Martínez R D, Rumiano F J L, Rechimont R, Rabasa S. L. 1989. "Bovino Criollo Argentino biotipo patagónico: Descripción y conservación". Actas XX Congreso Argentino de Genética. Bahía Blanca provincia de Buenos Aires Argentina.Pag.105-106

Romero Aguirre, M.A. 1957. Ganadería Argentina, su desarrollo e industrialización. Historial de la ganadería y de la industria Frigorífica en la República Argentina. Compañía Swift de la Plata S. A.137 pp.

Rouse J E. 1977. The Criollo. Spanish Cattle in the Americas. University of Oklahoma Press Norman $303 \mathrm{pp}$.

Ruffini M. 2003. Estado nacional y territorios. Notas sobre la economía rionegrina en la etapa de los gobiernos militares (1884-1898). Mundo Agrario, Vol. 3, Nro.6. 31 pag. Universidad Nacional de La Plata. http://www.mundoagrario.unlp.edu.ar/

Sesto C. 2004. El cambio racial del vacuno. ¿Un fenómeno de la demanda interna (1856-1894)?. Anuario del Instituto de Historia Argentina Nro. 4. Pág. 235-271.

Teira G. 2004. Actualidad y perspectivas de un componente principal de la calidad de carnes bovinas: la terneza. Revista Ciencia, Docencia y Tecnología No 28, Año XV, 215-244.

Tewolde, A. 1997. Los criollos bovinos y los sistemas de producción animal en los trópicos de América Latina. Archivos Latinoamericanos de Producción Animal. 5 (5):13-19.

Veniart J. 1993. Como se pobló la Patagonia con ganado bovino criollo. $X$ Jornadas Nacionales de Ganado Bovino Criollo. Jesús María Córdoba. En Ganado Bovino Criollo Tomo 5. Orientación Gráfica Editora. Pag.225-240 
Reis, F. A.; Costa, J. A. A.; Vargas Junior, F. M.; Ferreira, M. B. Sistema produtivo de ovinos pantaneiro em ILPF. In: Simpósio Internacional de Raças Nativas, 1., 2015, Teresina. Sustentabilidade e Propriedade Intelectual: anais. Piauí: SFA-PI, 2015. $8 \mathrm{f}$.

Santiago Filho, A.; Avaliação do desempenho sexual de carneiros do grupo genético nativo pantaneiro sulmato-grossense, com base na demonstração da libido, Universidade Anhanguera-Uniderp. Dissertação de mestrado. Campo Grande MS, 35p. 2010.

Silva, J.S.V.; Abdon, M.M. Delimitação do Pantanal brasileiro e suas sub-regiões. Pesq. agropec. bras., Brasilia, v.33, Número Especial, p.1703-171 1, 1998.
Simon, J. P. Efeito do flushing com ácidos graxos insaturados na função reprodutiva e produtiva em ovelhas pantaneiras. Universidade Federal de Mato Grosso do Sul. Tese 94 p. 2019.

Vargas Junior, F. M., Martins, C. F., Pinto, G. S., Ferreira, M. B., Ricardo, H. A., Leonardo, A. P., Fernandes, A. R. M., Teixeira, A. Carcass measurements, non-carcass components and cut production of local Brazilian Pantaneiro sheep and crossbreeds of Texel and Santa Inês with Pantaneiro. Small Ruminant Research, 124: 55-62, 2015. doi:10.1016/j.smallrumres.2014.12.007

Villafuerte, S. G. E. Sistemas de terminação de cordeiros do grupo genético pantaneiro. Embrapa Caprinos e Ovinos- dissertação (ALICE), 54p. 2016. 